\title{
Abordagem cirúrgica da constrição maxilar unilateral
}

Os métodos convencionais de expansão rápida da maxila visam o seu aumento transversal bilateralmente. Para alcançar uma expansão tanto bilateral quanto unilateral, Al-Ouf e colaboradores desenvolveram uma técnica e a publicaram no Journal of Craniomaxillofacial Surgery ${ }^{1}$. O guia da expansão é a estabilidade da sutura palatina mediana e, assim, emprega-se duas osteotomias de cada lado da sutura. O estudo incluiu 17 pacientes, 9 do gênero masculino e 8 do feminino, com média de idades de 30,7 anos. Avaliou-se a quantidade de expansão pelas distâncias intercaninos e intermolares - medidas antes e após o tratamento e aos 6 meses de acompanhamento. Em média, conseguiu-se 7,1 e 9,9mm de expansão nas regiões dos caninos e molares, respectivamente. A quantidade de recidiva foi mínima: $0,35 \mathrm{~mm}$ nos caninos e $0,8 \mathrm{~mm}$ nos molares. Em seis desses pacientes, foi realizada a expansão unilateral e o tratamento mostrou-se estável no período avaliado. Essa nova abordagem de problemas transversais em adultos, apesar de precisar de um maior embasamento científico, pode ser considerada para a prática clínica, uma vez que se mostrou efetiva e estável.

\section{Os benefícios da expansão maxilar na função respiratória de crianças e na prevenção de otite média recorrente}

Um grupo de pesquisadores publicou recentemente, na revista B-ENT, a experiência deles em tratar casos de otite média recorrente utilizando a expansão rápida da maxila ${ }^{2}$. Incluiu-se no estudo 27 crianças - 15 do gênero masculino e 12 do feminino - com média de idades de 7 anos. Esses apresentavam otite média recorrente associada à hipertrofia das adenoides e à Síndrome de Desenvolvimento Esquelético. Essa síndrome, descrita por Laptook ${ }^{4}$, consiste na constrição maxilar com elevação do assoalho nasal, mordida cruzada bilateral e palato ogival. As crianças foram submetidas à avaliação ortodôntica e otorrinolaringológica ao início e após seis e doze meses da expansão maxilar - realizada com Hyrax e ativações de um quarto de volta pela manhã e um quarto à noite. A terapia promoveu uma expansão da sutura palatina mediana e do assoalho nasal, além de reduzir o grau de hipertrofia das adenoides, melhorando a qualidade da respiração nasal. Também estirou os músculos elevador e tensor do véu palatino, o que restaurou a função do tubo auditivo, mesmo na presença de hipertrofia da adenoide. Esse foi um importante benefício, pois, mesmo após a cirurgia de remoção das adenoides, que normalmente é o procedimento de eleição, a disfunção do tubo auditivo pode permanecer. A expansão rápida da maxila pode, então, ser considerada um tratamento preventivo da otite média recorrente em crianças com alterações maxilares. Mais do que isso, esse artigo demonstra a necessidade de interação multidisciplinar e que os ortodontistas devem estar atentos também, quando examinarem crianças, a questões respiratórias. 


\section{O uso do laser Er:Yag na expansão cirúrgica da maxila}

Em adultos, a diminuição do diâmetro transversal em casos de hipoplasia maxilar é tratada com a expansão cirúrgica da maxila. Essa envolve osteotomias, para reduzir a resistência das suturas e facilitar a expansão. As vantagens que o laser Er:Yag pode agregar a essa fase do procedimento foram abordadas pelo pesquisador Giordano e seus colaboradores no artiqo que publicaram na revista Minerva Stomatologica, em junho desse $\mathrm{ano}^{3}$. Foi descrito um caso de expansão cirúrgica da maxila com o uso do laser Er:Yag. O laser auxiliou a promover osteotomias, em alvos específicos, sem induzir danos iatrogênicos aos tecidos moles. O tratamento ortodôntico consistiu na expansão maxilar - com uso de Hyrax - associada à protração maxilar com máscara facial. A protração terminou 60 dias após a cirurgia. Depois, o aparelho

\section{REFERÊNCIAS}

1. AL-OUF, K.; KRENKEL, C.; HAJEER, M. Y.; SAKKA, S. Osteogenic uni- or bilateral form of the guided rapid maxillary expansion. J. Craniomaxillofac. Surg., New York, 15 May 2009. Epub ahead of print.

2. DE STEFANO, A.; BAFFA, C.; CERRONE, D.; MATHUR, N.; CASCINI, V.; PETRUCCI, A. G.; NERI, G. Management of recurrent otitis media with rapid maxillary expansion: Our experience. B-ENT, Leuven, v. 5, no. 1, p. 13-17, 2009. ortodôntico fixo foi montado e o tratamento foi finalizado. Os exames radiográficos iniciais foram repetidos ao final da protração maxilar e após a conclusão do tratamento ortodôntico, que, ao todo, durou 18 meses. Os resultados do tratamento foram satisfatórios e similares aos relatados na literatura. Assim, o laser Er:Yag, nesse caso, possibilitou cortes mais precisos e menor probabilidade de efeitos colaterais nos tecidos moles. Isso otimiza tanto o procedimento cirúrgico quanto o pós-operatório do paciente. Certamente, mais estudos são necessários para atestar as vantagens do laser Er:Yag em comparação às brocas e serras convencionais, mas esse relato de caso já torna evidente como a tecnologia pode auxiliar nos procedimentos odontológicos e deve estar incluída na rotina clínica.
3. GIORDANO, M.; TURATTI, G.; PARODI, G.; LUCIANI, M.; LAGANÀ, D. The maxillary protraction treatment: Description of a laser Er:Yag-assisted surgical technique. Case report. Minerva Stomatol., Torino, v. 58, no. 6, p. 307-315, June 2009.

4. LAPTOOK, T. Conductive hearing loss and rapid maxillary expansion. Report of a case. Am. J. Orthod., St. Louis, v. 80, no. 3, p. 325-331, 1981.

\section{Patrícia Medeiros Berto \\ Especialista em Ortodontia - Universidade Federal de Goiás. Clínica privada em Ortodontia - Brasília/DF.}

Endereço para correspondência

SCN Brasília Shopping sala 408

CEP: 70.715-900 - Brasília / DF

E-mail: pmberto@ig.com.br 